\title{
Endocannabinoid Hedonic Hotspot for Sensory Pleasure: Anandamide in Nucleus Accumbens Shell Enhances 'Liking' of a Sweet Reward
}

\author{
Stephen V Mahler*,', Kyle S Smith' and Kent C Berridge' \\ 'Department of Psychology, The University of Michigan, Ann Arbor, MI, USA
}

\begin{abstract}
Cannabinoid drugs such as $\Delta^{9}$-THC are euphoric and rewarding, and also stimulate food intake in humans and animals. Little is known about how naturally occurring endogenous brain cannabinoids mediate pleasure from food or other natural sensory rewards. The taste reactivity paradigm measures effects of brain manipulations on affective orofacial reactions to intraorally administered pleasant and unpleasant tastes. Here we tested if anandamide microinjection into medial nucleus accumbens shell enhances these affective reactions to sweet and bitter tastes in rats. Anandamide doubled the number of positive 'liking' reactions elicited by intraoral sucrose, without altering negative 'disliking' reactions to bitter quinine. Anandamide microinjections produced Fos plumes of approximately $0.02-1$ mm ${ }^{3}$ volume. Plume-based maps, integrated with behavioral data, identified the medial shell of accumbens as the anatomical hotspot responsible for hedonic amplification. Anandamide produced especially intense hedonic enhancement in a roughly $1.6 \mathrm{~mm}^{3}$ 'hedonic hotspot' in dorsal medial shell, where anandamide also stimulated eating behavior. These results demonstrate that endocannabinoid signals within medial accumbens shell specifically amplify the positive hedonic impact of a natural reward (though identification of the receptor specificity of this effect will require future studies). Identification of an endocannabinoid hotspot for sensory pleasure gives insight into brain mechanisms of natural reward, and may be relevant to understanding the neural effects of cannabinoid drugs of abuse and therapeutic agents.
\end{abstract}

Neuropsychopharmacology (2007) 32, 2267-2278; doi:I0.1038/sj.npp. I301376; published online 4 April 2007

Keywords: endocannabinoid; taste reactivity; reward; marijuana; munchies; pleasure

\section{INTRODUCTION}

Cannabinoids are known for their rewarding effects and for their ability to stimulate increases in food intake (eg the marijuana 'munchies'). In animal studies of appetite, infusions of cannabinoid drugs such as $\Delta^{9}$-THC, or of endogenous cannabinoid neurotransmitters such as anandamide stimulate eating behavior and food intake (Williams et al, 1998; Williams and Kirkham, 1999; Di Marzo and Matias, 2005; Pagotto et al, 2006). In human clinical applications, cannabinoid agonist drugs stimulate appetite in hypophagic patients, and conversely, cannabinoid antagonist drugs are currently of interest for potential therapeutic roles to suppress consumption as dieting aids and addiction treatments (Di Marzo and Petrocellis, 2006).

\footnotetext{
*Correspondence: SV Mahler, Department of Psychology, The University of Michigan, 530 Church Street, Ann Arbor, MI 48I09, USA, Tel: + I 734764 8078; Fax: + I 734763 7480,

E-mail: svmahler@umich.edu

Received 8 August 2006; revised 12 January 2007; accepted I 5 January 2007
}

Cannabinoid receptors (CB1 and/or CB2) are present throughout the limbic forebrain, including the striatum and nucleus accumbens (Herkenham et al, 1991; Moldrich and Wenger, 2000; Fusco et al, 2004; Gong et al, 2006). Many functional effects of endocannabinoids in brain are thought to occur via CB1 receptors (Piomelli, 2003). CB1 receptors are located on GABAergic presynaptic axons in the nucleus accumbens shell (Matyas et al, 2006), and are often colocalized with $\mu$ opioid receptors at the same synapses and in the same cells in striatum (Pickel et al, 2004; Schoffelmeer et al, 2006). CB2 receptors have also been reported to occur on glial cells and neurons in ventral striatum, though less is known about their synaptic localization or function (Gong et al, 2006).

Regarding the relation between reward and appetite effects, a promising hypothesis is that cannabinoid drugs might act in the brain to increase hedonic impact or palatability of the taste of foods, as part of the mechanism by which they increase appetite and food intake (Cooper, 2004; Jarrett et al, 2005; Kirkham, 2005). Systemic and ICV $\Delta^{9}$-THC potently increase intake of sweet foods more than less palatable foods (Koch and Matthews, 2001), and enhance voluntary licking bouts at a sucrose spout in a 
manner consistent with palatability enhancement (Higgs et al, 2003). Microinjections of the endocannabinoid 2-AG directly into the medial shell of nucleus accumbens similarly increases food intake in rats (Kirkham et al, 2002). Conversely, food-related manipulations, such as deprivation and satiety, or access to a palatable diet produce changes in $\mathrm{CB} 1$ receptor density and in dialysate levels of endogenous anandamide and 2-AG in nucleus accumbens and other brain areas, and modulate appetite stimulation by cannabinoids (Di Marzo et al, 2001; Harrold et al, 2002; Kirkham et al, 2002). Most relevant to this study, systemic administration of $\Delta^{9}$-THC in rats is reported to cause eventual increase in affective orofacial 'liking' reactions elicited by the taste of sucrose, suggesting enhancement of taste palatability (Jarrett et al, 2005).

The brain substrates of cannabinoid hedonic effects are so far unknown, but such observations give rise to the hypothesis examined here: that endogenous cannabinoid neurotransmission in limbic brain structures such as nucleus accumbens mediates the hedonic impact of natural rewards like sweetness. The nucleus accumbens is an especially likely candidate for cannabinoid mediation of hedonic impact because it is known to contribute to the generation by other neurotransmitters of hedonic affect ('liking') and appetitive motivation ('wanting') for food and drug rewards (Berridge and Robinson, 2003).

The medial shell region of nucleus accumbens appears particularly important for amplifying the hedonic impact of rewarding incentives. For example, a $1 \mathrm{~mm}^{3}$ 'hedonic hotspot' was recently found in the medial shell where $\mu$ opioid receptor activation by DAMGO microinjections tripled positive 'liking' orofacial reactions that are elicited by sucrose taste in rats (Peciña and Berridge, 2005), and stimulated food intake (though the intake 'wanting' site extended further) (Bakshi and Kelley, 1993; Zhang and Kelley, 2000; Peciña and Berridge, 2005). Opioid and endocannabinoid neurotransmissions are known to positively interact (Tanda et al, 1997; Kirkham and Williams, 2001; Navarro et al, 2001; Rowland et al, 2001; Williams and Kirkham, 2002b; Verty et al, 2003; Solinas and Goldberg, 2005; Vigano et al, 2005; Caille and Parsons, 2006; Cota et al, 2006), raising the possibility that endocannabinoid receptor activation might increase 'liking' for natural rewards in the same hedonic hotspot of the medial accumbens shell where opioids do so.

Based on these considerations, we tested whether endogenous cannabinoid neurotransmission in the medial shell of nucleus accumbens mediates the hedonic impact of a natural sensory pleasure, sweetness. Microinjections of anandamide into the medial shell multiplied positive 'liking' reactions to sucrose taste (a measure based on homologous orofacial expressions of affective 'liking' $v s$ 'disliking' consummatory reactions that are elicited by tastes in human infants, apes, monkeys, and rats (for a review, see Berridge (2000), and Supplementary Movie 1 online). To assess where in the brain anandamide acted to enhance 'liking' for sweet hedonic impact, we mapped the substrate responsible for hedonic enhancement, using local Fos plumes produced by equivalent anandamide microinjections to identify where microinjections acted. Our results indicate that natural 'liking' reactions to sweetness, as well as eating behavior, are amplified by endogenous cannabi- noid signals in nucleus accumbens, especially within a hedonic hotspot in the dorsal medial shell.

\section{MATERIALS AND METHODS}

\section{Subjects}

Sprague-Dawley rats ( $n=62$, male, $250-400$ g, pair housed) were given microinjections into the medial accumbens shell or control structures of vehicle or anandamide doses. Groups of rats were subsequently tested for taste reactivity to sucrose or quinine infusions into the mouth and for voluntary feeding behavior. Each behaviorally tested rat received vehicle and every dose for its group in counterbalanced order spaced at least $48 \mathrm{~h}$ apart. Different groups were used to test (1) time course of anandamide 'liking' effects ( $n=11$; anatomical control sites: $n=5)$, (2) balance of anandamide effects on sucrose 'liking' $v s$ quinine 'disliking' $(n=19)$, (3) food and water intake effects $(n=11)$, and (4) Fos plume measurements under conditions equivalent to day 1 of behavioral testing $(n=16)$. These groups were separated in order to ensure that no rat received more than four microinjections (to avoid damage accumulation), and to ensure that Fos and behavior were measured under identical conditions when drug impact was maximal, as explained below.

Measurement of anandamide's maximal impact on 'liking', food intake, and Fos plumes was achieved by a split-and-recombine design, in which rats were assigned upon surgical implantation to either a behavioral test group ( $n=46$ behavioral animals, which then also received oral cannulae) or a Fos plume test group ( $n=16$ Fos animals). Placements in medial shell were similar for both groups, which were treated identically after surgery. Fos plumes were assessed under conditions similar to the first test day of the behavioral group to allow maximal impact of anandamide microinjections. The reason for the split was to ensure measurement of initial maximum drug impact, and avoid the diminishment in efficacy of drug that might occur after several repeated microinjections. The possibility that repetition may reduce drug impact on local tissue creates a type of 'uncertainty principle' regarding measurement of maximum impact: one can measure either the behavioral maximum or the Fos plume maximum in a repeated-measures experiment but not both. The reason for the recombination was to project the observed behavioral 'liking' and 'wanting' effects onto the precise locations where anandamide microinjections were likely to have acted based on observed Fos plumes.

Splitting allowed measurement of both maximums, while still allowing repeated-measures comparison in the same rat of anandamide and vehicle effects on hedonic impact or intake. Recombination allowed integration of behavioral and Fos data, obtained under similar conditions, into the same Fos plume maps of anandamide effects on 'liking' reactions and on food intake.

\section{Surgery}

Rats were anesthetized with ketamine $(80 \mathrm{mg} / \mathrm{kg})$, xylazine $(5 \mathrm{mg} / \mathrm{kg})$, and pretreated with atropine $(0.04 \mathrm{mg} / \mathrm{kg})$. Using a stereotaxic device, rats were implanted with bilateral 23 ga 
microinjection guide cannulae, $14 \mathrm{~mm}$ in length, aimed at a level $2.5 \mathrm{~mm}$ anterodorsal to the accumbens shell. A slanted cannula track was used to avoid penetrating the lateral ventricles (slanted skull = incisor bar: $+5.0 \mathrm{~mm}$; coordinates: AP: $+3.4-+2.4 \mathrm{~mm}$ anterior to Bregma, ML: $\pm 1.0 \mathrm{~mm}$, DV: $4.7-6.0 \mathrm{~mm}$ below skull surface (Paxinos and Watson, 2005). To provide anatomical control sites for behavioral studies, five additional rats were implanted with guide cannulae in other brain structures outside the accumbens, including sites along the cannulae tracks that were dorsal or anterior to accumbens. Anatomical control sites were in anterior prelimbic cortex $(n=2$, AP: +3.1, ML: \pm 1.0 , DV: -2.0$)$, dorsal striatum $(n=1$, AP: $+1.6, \mathrm{ML}$ : \pm 3.0 , DV: -3.0 ), or anterior ventral pallidum (caudal to nucleus accumbens; $n=2$, AP: +0.4 , ML: \pm 1.1 , DV: -5.5 ). Microinjection guide cannulae were secured with skull screws and dental cement, and occluded with steel stylets.

In the same surgery, all rats used for taste reactivity testing were also implanted with bilateral oral cannulae (PE100 tubing) to allow oral infusions of sucrose or quinine solutions during taste reactivity testing (rats used for Fos did not receive oral cannulae). Oral cannulae were inserted lateral to the first maxillary molar, threaded behind the zygomatic arch, and exited through the dorsal head where they were cemented to skull screws (Grill and Norgren, 1978; Berridge et al, 1984). All rats were allowed to recover before testing for at least 7 days after surgery, and were habituated to their taste reactivity or food intake test chambers for $30 \mathrm{~min}$ on 4 consecutive days prior to the first test. On the last day of habituation, all rats received one $0.5 \mu$ l saline microinjection following procedures described above to acclimate them to microinjections themselves.

\section{Drugs and Microinjections}

Anandamide in a bioavailable aqueous soya suspension (Tocrisolve, Tocris) was diluted to dose with $0.9 \%$ saline solution. Tocrisolve vehicle was similarly diluted for control vehicle microinjections. On test days, rats were gently hand held while stylets were removed. Rats then received bilateral microinjections $(0.5 \mu \mathrm{l}$ volume per side over a $90 \mathrm{~s}$ period) of vehicle or anandamide via a stainless-steel injector cannula (29 ga), which extended $2.5 \mathrm{~mm}$ beyond the guide cannulae into the target site. Microinjector cannulae were held in place for an additional $1 \mathrm{~min}$ to allow for drug diffusion, then stylets were replaced and rats were immediately placed into their taste reactivity or food intake test chamber.

\section{Behavioral Taste Reactivity Tests}

For taste reactivity tests, after rats received a bilateral microinjection into nucleus accumbens or a control structure, a tastant delivery tube was connected to their oral cannulae, and rats were placed in the test chamber. To elicit taste reactivity patterns, $1 \mathrm{ml}$ sucrose or quinine solutions were infused over $1 \mathrm{~min}$ through the oral cannula at various times after brain microinjection, as described below. A digital video camera recorded orofacial reactions to all infusions, via an angled mirror under the transparent taste reactivity chamber floor.
Rats in the time-course group received microinjections of vehicle or anandamide $(0,25$, and $50 \mathrm{ng})$ in counterbalanced order over 3 test days separated by at least $48 \mathrm{~h}$, and were tested for sucrose reactivity at 15,30 , and $45 \mathrm{~min}$ after microinjection $(n=16)$. Rats in the sucrose $v s$ quinine comparison group similarly received microinjections of vehicle or anandamide $(0,12.5,25$, or $50 \mathrm{ng} ; n=19)$ over 4 test days spaced $48 \mathrm{~h}$ apart. Because initial time-course results indicated that anandamide effects were maximal and constant 30-45 min after microinjection, rats in the comparison group received an oral infusion of $1 \%$ sucrose solution (1 $\mathrm{ml}$ volume, $1 \mathrm{~min}$ duration) at $30 \mathrm{~min}$ after drug, and received a second oral infusion of $3 \times 10^{-4} \mathrm{M}$ quinine ( $1 \mathrm{ml}$ volume, $1 \mathrm{~min}$ duration) $15 \mathrm{~min}$ later at $45 \mathrm{~min}$ after the drug. This order of testing was used to ensure that 'liking' reactions to sucrose were always pure and uncontaminated by any prior taste on that day, because positive hedonic 'liking' reactions are generally more vulnerable to disruption than negative 'disliking' reactions, and because it is identical to the procedure used in a previous mapping study of the accumbens hedonic hotspot (Peciña and Berridge, 2005).

\section{Taste Reactivity Video Scoring}

Hedonic, aversive, and neutral response patterns were later scored off-line in slow motion (frame by frame to $1 / 10$ th actual speed) by a trained observer who was blind to experimental condition, using time bin scoring procedures developed to assess hedonic vs aversive taste valuations (Berridge et al, 1984; Berridge, 2000). Hedonic responses included rhythmic midline tongue protrusions, lateral tongue protrusions, and paw licks. Aversive responses included gapes, head shakes, face washes, forelimb flails, and chin rubs (see Supplementary Movie 1 online). Neutral responses, which are less consistently linked to hedonic/ aversive taste valuation, included passive dripping of solution out of the mouth, ordinary grooming, and rhythmic mouth movements. All video analyses were conducted blind to the microinjection contents and cannula placement using Observer software (Noldus, Netherlands).

A time bin scoring procedure was used to ensure that taste reactivity components of different relative frequency were balanced in their contributions to the final affective hedonic/aversive totals (Berridge, 2000). For example, rhythmic mouth movements, passive dripping of solution, paw licking, and grooming reactions typically occur in long bouts, and were thus scored in $5 \mathrm{~s}$ time bins (up to $5 \mathrm{~s}$ continuous bout duration equaled one occurrence). Tongue protrusions, which occur in shorter bouts, were scored in $2 \mathrm{~s}$ time bins. The other behavioral components (lateral tongue protrusions, gapes, forelimb flails, head shakes, chin rubs) typically occur as discrete events and were therefore scored as single occurrences each time they occurred (eg one gape equaled one occurrence). Individual totals were calculated for hedonic $v s$ aversive categories for each rat by adding all response scores within an affective category for that rat. Finally, the hedonic 'liking' reaction total was defined as the sum of scores for lateral tongue protrusions, rhythmic tongue protrusions, and paw licks. Similarly, the aversive 'disliking' total was the sum of gapes, head shakes, face washes, forelimb flails, and chin rubs. 


\section{Histology}

After the completion of testing, rats used for behavioral testing were deeply anesthetized with sodium pentobarbital $(0.2 \mathrm{~g} / \mathrm{kg})$, microinjected with $0.2 \mu \mathrm{l}$ black ink, and their brains were extracted. Brains were sectioned with a freezing microtome into $60 \mu \mathrm{m}$ coronal slices, stained with cresyl violet, and mapped for microinjection center locations according to Paxinos and Watson (2005).

\section{Behavioral Eating Tests}

To confirm that anandamide selectively increased food intake, behavioral eating and drinking effects were assessed in an additional group of rats in a voluntary food and water intake test $(n=11)$. After vehicle or anandamide $(25 \mathrm{ng})$ microinjections, rats were placed in clear cages that contained food, corncob bedding and a water spout. Premeasured chow pellets and water were freely available for a $1 \mathrm{~h}$ voluntary feeding test. Rats were videotaped during the test for subsequent off-line scoring of eating, drinking, and other behaviors during the $1 \mathrm{~h}$ test. Videotapes were later scored in slow motion for time spent eating and drinking, object sniffing, gnawing, and carrying, sleeping, and other behaviors by observers blind to the experimental condition.

\section{Fos-Like Protein Immunohistochemistry}

Rats in the Fos plume group $(n=16)$ were handled for 3 days for $10 \mathrm{~min}$ each, similar to the behavioral groups, and then microinjected bilaterally in the accumbens shell with one of three doses of anandamide or vehicle as described above (12.5 ng, $n=3 ; 25 \mathrm{ng}, n=4 ; 50 \mathrm{ng}, n=3$; veh, $n=6$; normal uninjected tissue, $n=4)$. Placements were bracketed throughout the medial shell similarly to the behavioral group, and it was later confirmed that every behavioral group site was within $1 \mathrm{~mm}$ of a corresponding Fos group site. Fos-like protein expression was harvested under conditions identical to the first day of testing for the behavioral group.

Rats were deeply anesthetized with sodium pentobarbital $(0.2 \mathrm{~g} / \mathrm{kg}) 75 \mathrm{~min}$ after microinjection, since translation of c-fos mRNA to Fos protein is maximal between 60 and $120 \mathrm{~min}$ (Muller et al, 1984). After transcardial perfusion, brains were removed and placed in $4 \%$ paraformaldehyde for $2 \mathrm{~h}, 30 \%$ sucrose overnight, and then sectioned at $40 \mu \mathrm{m}$ and stored in $0.2 \mathrm{M} \mathrm{NaPb}, \mathrm{pH}$ 7.4. To visualize Fos-like immunoreactivity, we used the avidin-biotin procedure (Hsu et al, 1981). Brain sections were immersed in blocking solution (3\% normal goat serum (NGS) and $0.3 \%$ Triton X100 in Tris PBS (TPBS)) for $1 \mathrm{~h}$ and then incubated at room temperature for $24 \mathrm{~h}$ with a rabbit polyclonal antiserum directed against the $\mathrm{N}$-terminal region of the Fos gene (dilution of $1: 5000$ in TPBS, 1\% NGS, and 0.3\% Triton X100; Sigma). To reduce background staining, the antiserum was preabsorbed with acetone-dried rat liver powder overnight at $4{ }^{\circ} \mathrm{C}$. After the primary antibody incubation, tissue was exposed to goat anti-rabbit, biotinylated secondary IgG (diluted 1:200; Santa Cruz Biochemicals, Santa Cruz, CA) and then to avidin-biotin-peroxidase complex for $1 \mathrm{~h}$ at room temperature. A nickel diamino- benzidine (Nickel-DAB) glucose oxidase reaction was used to visualize Fos-like immunoreactive cells. Finally, sections were washed in Tris buffer, mounted from PBS, air-dried, dehydrated in alcohol, cleared in xylene, and coverslipped. Fos-like immunoreactivity was visualized using a Leica (Nussloch, Germany) microscope coupled to a SPOT RT slider (Diagnostic Instruments, Sterling Heights, MI) using SPOT software (SPOT version 3.3). Cannulae placements were localized by superimposing the image from a lowmagnification light microscope onto a computerized brain atlas (Paxinos and Watson, 2005).

Some additional brains were sliced on the sagittal plane and stained for Substance $P$ to help localize the position of mapped Fos plumes within the borders of nucleus accumbens shell (Berridge et al, 1997) (Figure 1). The procedures for Substance P staining were identical to Fos immunohistochemistry except that the primary antibody was for Substance P (Immunostar; 1:2000 concentration).

\section{Fos Plume Maps of Anandamide-Induced Neuronal Activation Spread}

Our procedure for measuring drug-induced Fos plumes immediately surrounding a microinjection site followed procedures described previously (Peciña and Berridge, 2000, 2005; Smith and Berridge, 2005). Observed Fos plume measurements from the Fos group were averaged to determine mean volumes for each Fos intensity zone, assuming a spherical shape of functional drug spread. Averaged plume radii for each zone were projected onto the microinjection center from the behavioral group to depict extent of activation spread, and used to assign symbol sizes for maps. Behavioral data from each microinjection site were used to assign the color of its symbol on the map that coded intensity of 'liking' or 'wanting' effects produced by microinjection at that site (details below).

To quantify spread of drug-induced neuronal activation, Fos-labeled cells on tissue surface near the microinjection site were visualized with $\times 5-\times 40$ magnification and counted individually within blocks $(125 \mu \mathrm{m} \times 125 \mu \mathrm{m})$ at locations spaced at $125 \mu \mathrm{m}$ intervals along each of the seven radial arms emanating from the center of the microinjection site $\left(45,90,135,180,225,270,315^{\circ}\right.$; see Figure 1$)$. To establish baselines for comparison to drug plumes, control values for Fos densities were measured (1) in normal nucleus accumbens shell tissue of intact brains to assess normal baseline expression in 'virgin tissue' that was not damaged by surgical intrusion or gliosis and (2) around the site of vehicle microinjections to assess cannula track and vehicle-induced baseline Fos expression. Fos densities were also measured around the site of anandamide microinjections to assess drug-induced elevations of local Fos expression (Figure 1). In this study, we improved the sensitivity of detection of elevated Fos expression, mapping $2 \times$ and $3 \times$ elevations over control levels in addition to higher levels, compared to previous studies that detected $>5 \times$ as the lowest increase over control levels (Peciña and Berridge, 2005; Smith and Berridge, 2005).

Anandamide Fos plumes (12.5, 25, and $50 \mathrm{ng}$ ) were mapped in two ways: (1) as $2 \times, 3 \times, 5 \times$, and $10 \times$ vehicle-relative increases caused by anandamide, and (2) as absolute $2 \times, 3 \times, 5 \times$, and $10 \times$ increases above normal 


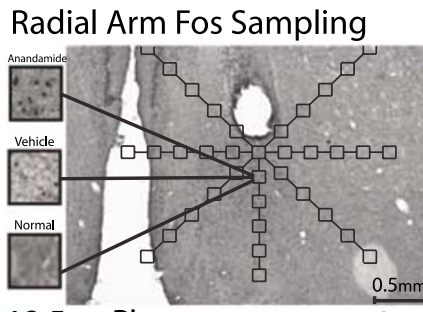

Vehicle Plume

Sample Fos Expression

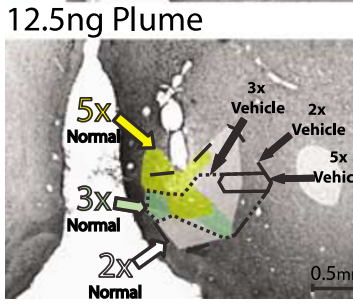

25ng Plume
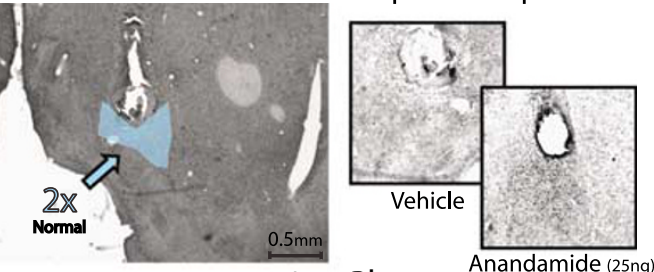

50ng Plume
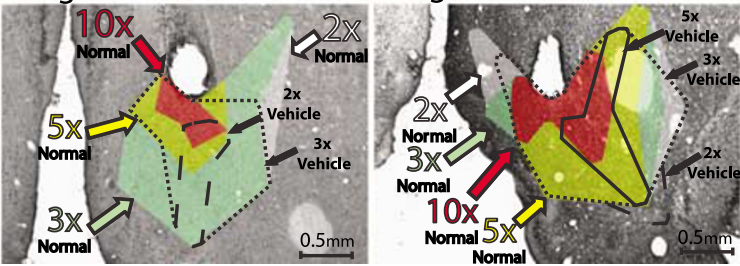

Figure I Anandamide Fos plume examples. Radial arm Fos sampling: Illustrates the Fos sampling method, in which radial arms for sampling extend from center of microinjection, viewed in the coronal plane (Fos-expressing neurons are counted in I $25 \times 125 \mu \mathrm{m}$ blocks on arms spaced at I $25 \mu \mathrm{m}$ intervals; $\times 5$ magnification). Insets show sample tissue blocks from anandamide or vehicle plumes and from a normal uninjected brain. Vehicle plume: Small vehicle-induced Fos plume, mapped as low $(\times 2)$ Fos elevation relative to normal tissue. Sample Fos expression: Neurons expressing Fos-like activity in medial shell of nucleus accumbens after anandamide $(25 \mathrm{ng})$ or vehicle microinjection ( $\times 5$ magnification, contrast enhanced in both panels). Anandamide Fos plumes: Fos plume examples for each dose (12.5, 25, 50 ng; brains taken 75 min after microinjection); color denotes plume as mapped by Fos elevation over normal expression (percentage increase over vehicle levels); lines denote plume as mapped by Fos elevation over vehicle microinjection levels at equivalent boxes and sites.

uninjected tissue. In both cases, the distance of $2 \times$ spread from the microinjection site was measured on each radial arm. Spread extended to the last box expressing greater than or equal to $2 \times$ elevation. The distance from the injection site for $2 \times$ spread was then averaged for all seven radial arms, providing a final radius-cubed zone of $2 \times$ elevation. The same procedure was followed for $3 \times, 5 \times$, and $10 \times$ zones (distance from center in which boxes expressed greater than or equal to the elevation). Thus, anandamide-evoked increases in Fos were compared to normal and vehicle Fos levels at the same site within medial accumbens shell, and maps were created of lowest, low, moderate, and high Fos elevation zones for each of the three anandamide doses.

Fos data were recombined with behavioral data in the next mapping stage. The radii of Fos plumes were averaged for each elevation zone, and each zone was assigned a hexagon map symbol of a size based on Fos plume radii. Behavioral effects of each microinjection site were represented by the colors of plume-derived symbols (Figures 2, 4-5; Supplementary Figures S2, S3, S5 online). Each plume symbol in a map illustrates three important pieces of information: the location of microinjection in a particular rat tested for behavior, the intensity of behavioral effects of anandamide on food reward 'liking' or 'wanting' for that rat, and the size of the local neuronal modulation implicated in anandamide's effects at that site (based on average Fos plume radii). The bilateral cannulae for each rat were collapsed into one unilateral map and plotted separately to depict every placement (two sites per rat). Each site shows three concentric hexagon symbols, representing the average size of plume zones of Fos elevation: inner hexagon $=$ intense Fos elevation; intermediate hexagon $=$ moderate; outer hexagon $=$ low or lowest Fos elevation. Each hexagon is color coded for the magnitude of anandamide's behavioral effects on 'liking' reactions to sucrose, 'disliking' reactions to quinine, or food intake (Peciña and Berridge, 2000, 2005; Smith and Berridge, 2005). Separate maps were plotted in sagittal, coronal, and horizontal planes to construct a three-dimensional database of the position of Fos plumes in the brain and the location of functional hotspots (Paxinos and Watson, 1998) (Figure 2).

\section{Statistical Analyses}

All behavioral analyses were two-tailed and $\alpha$ was always set at $p<0.05$. Repeated measures ANOVAs were used for the time-course taste reactivity data $(0,25$, and $50 \mathrm{ng}$ doses $\times 15,30,45 \mathrm{~min}$ time points after drug), sucrose-quinine taste reactivity data $(0,12.5,25$, and $50 \mathrm{ng}$ dose; analyzed separately for sucrose and quinine tastes), and food and water intake data ( 0 and $25 \mathrm{ng}$ doses; analyzed separately for food and water). To describe anandamide behavioral effects as percentage increase over vehicle levels, a constant value of 1 was added to every datum to avoid the problem of calculating percentage increases over zero for rats with low baselines. Between-subjects ANOVAs were used to determine anatomical location effects of microinjection sites (dorsal $v s$ ventral). For anatomical localization and hedonic component analyses, all $30 \mathrm{~min}$ time-point sucrose taste reactivity data were combined because preliminary analysis showed no differences existed between groups in anandamide effects on hedonic taste reactivity $30 \mathrm{~min}$ after 25 and $50 \mathrm{ng}$ anandamide. Paired samples $t$-tests were used to test anandamide ( 0 and $25 \mathrm{ng}$ ) effects on eating behavior. Bonferroni corrected, paired samples $t$-tests and Tukey post hoc tests were employed to determine the nature of main effects and interactions after significant ANOVA outcomes.

\section{RESULTS}

\section{Fos Plume Mapping}

Fos plume maps helped identify where a drug microinjection acted on surrounding neural tissue, and where it stopped acting, as described in previous studies (Peciña and 


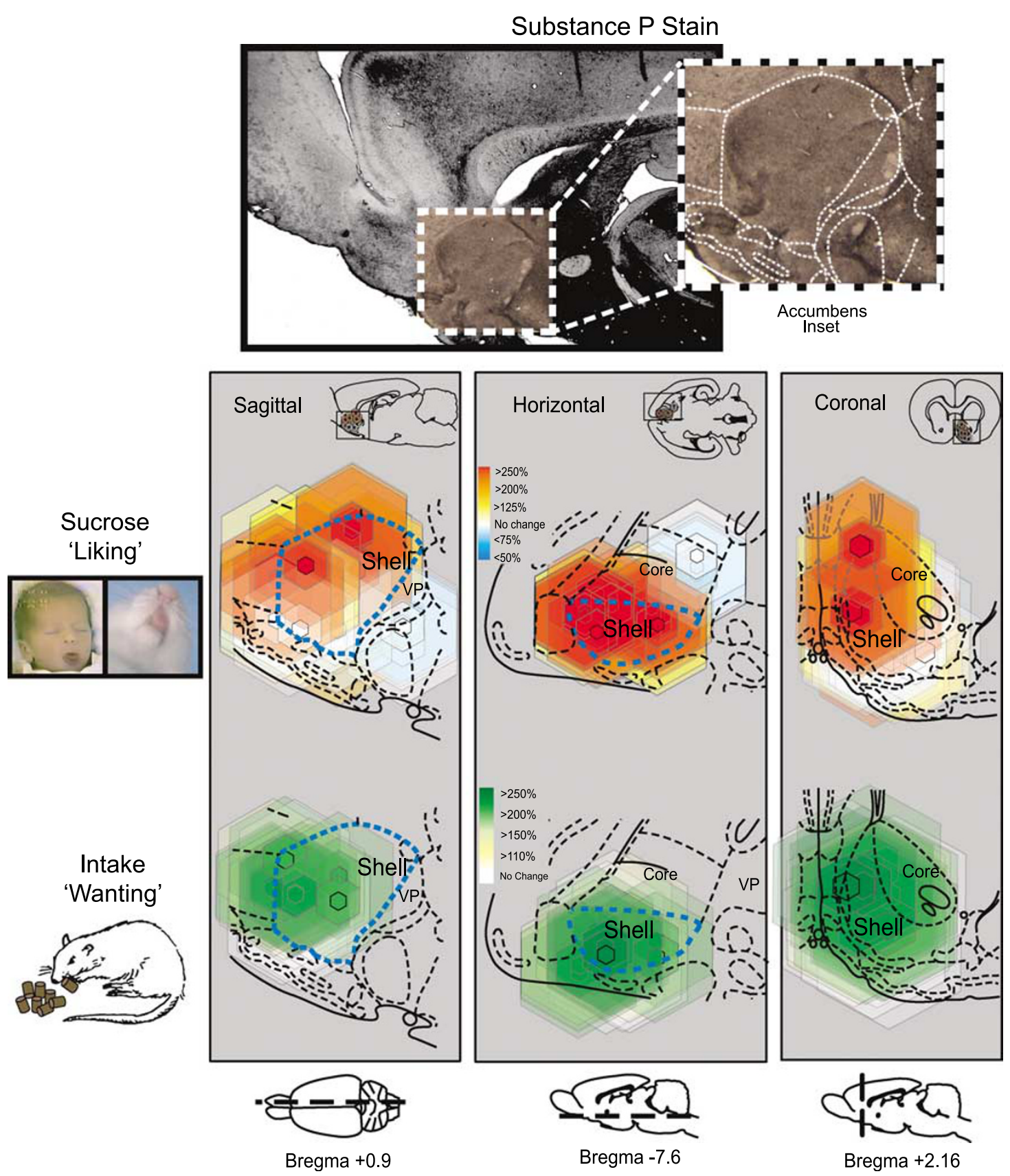

Figure 2 Summary Fos plume maps for hedonic 'liking' and food intake enhancements produced by anandamide in medial shell. Anandamide hotspots are mapped based on behavioral 'liking' or eating effects elicited at the mapped microinjection site (color) and on average Fos plumes measured at similar sites (size). Anatomical borders are visualized with Substance $P$ stain, and inset shows mapping area within larger brain (top). Lower columns show hotspots in sagittal, horizontal, and coronal planes of nucleus accumbens shell. Sucrose 'liking' summary (middle): Anandamide amplifies 'liking' reactions to sucrose taste especially in dorsal hotspot (all doses collapsed; all at 30 min time point). Symbol colors denote intensity of increase in number of positive 'liking' reactions, calculated as percent change from control vehicle injections at the same site. Inner symbols show average diameter of uninjected tissue-relative Fos plume intense centers $(10 \times)$, surrounded by semitransparent halos that show moderate elevation zone $(>5 \times)$, and lowest zone $(>2 \times)$. Food intake (bottom): Anandamide stimulates food intake (grams consumed in I h). Each unilateral cannula placement is represented with a symbol ( $25 \mathrm{ng}$ only). Symbol colors similar to above, and symbol size logic same as above. Note that eating effects were strong throughout the shell, whereas 'liking' sites were strongest in the dorsal half of shell.

Berridge, 2000, 2005; Ikemoto and Wise, 2004; Smith and Berridge, 2005). Anandamide microinjections may cause local Fos induction either directly by stimulating cannabinoid or other receptors on the neurons that express Fos, or indirectly by modulating neighboring neurons that in turn activate adjacent Fos-expressing neurons via local circuits. In either case, drug-induced Fos plumes reflected local spheres of modulated neuronal function. Therefore, plumes indicated the functional zones likely to be responsible for behavioral effects of anandamide microinjections, even if functionally inert levels of drug drifted farther.

Microinjections of anandamide produced roughly spherical and concentric zones of Fos enhancement: small inner zones of intense elevations of Fos expression, surrounded by larger 
zones of moderate, low, and lowest elevations (Figure 1). The inner intense plume was defined as the zone in which Fos expression was increased by $>10 \times$ above control 'normal' accumbens levels from uninjected rats, or above vehicle microinjection levels. A moderate Fos activation zone was defined as $>5 \times$ over normal levels or vehicle levels, a low Fos elevation zone was defined as $>3 \times$ over normal accumbens or vehicle levels, and the lowest Fos elevation zone was defined as $>2 \times$ over normal or vehicle levels. Vehicle injections induce a small area of Fos expression immediately around the center of the injection site (mean radius $0.27 \pm 0.06 \mathrm{~mm}$ of $2 \times$ Fos elevation over normal uninjected tissue levels), perhaps due to vehicle injection pressure, or cannula-related damage. The ability of vehicle to produce Fos plumes, even though small and low in intensity, places a ceiling on drug-induced Fos increases relative to levels measured around the tip of a vehicle microinjection.

The lowest $12.5 \mathrm{ng}$ dose of anandamide produced mean plume volumes in medial shell ranging from an intense center sphere, $4189 \pm 4189 \mu \mathrm{m}^{3}$ in volume (or $4.189 \times$ $10^{-6} \mathrm{~mm}^{3}$ at 1 billion cubic microns per $\mathrm{mm}^{3}$; mapped by $>10 \times$ normal tissue criterion) to an outer plume volume of $2.95 \pm 0.01 \mathrm{~mm}^{3}$ (mapped by $>2 \times$ increase over normaltissue criterion; $1.5 \pm 0.07 \mathrm{~mm}$ for $>2 \times$ increase over vehicle). The 25 and $50 \mathrm{ng}$ doses produced slightly larger Fos plume volumes, having intense $>10 \times$ Fos elevation centers of $0.017 \pm 0.0001 \mathrm{~mm}^{3}$ (25 ng dose) to $0.024 \pm$ $0.024 \mathrm{~mm}^{3}$ (50 ng dose), and outer total volumes of up to $3.05 \pm 0.001 \mathrm{~mm}^{3}$ (50 ng; mapped by $>2 \times$ normal tissue criterion; $1.91 \pm 0.002 \mathrm{~mm}^{3}$ relative to vehicle: see Supplementary Table 1 online for complete plume radius and volume data). We estimated the entire unilateral accumbens medial shell to be roughly $3 \mathrm{~mm}^{3}$ in tissue volume, and so these Fos plume volumes meant that the intense center of a typical anandamide plume filled about $1 \%$ of medial shell volume (center $=$ where Fos was at least $10 \times$ above normal), whereas the outer Fos plume (where Fos was doubled above vehicle plume or above normal tissue, respectively) spread through nearly $70-100 \%$ of medial shell volume.

\section{Anandamide Enhances Sucrose Hedonic Impact}

Anandamide microinjections in medial shell caused overall increases of $130-210 \%$ in the number of positive hedonic reactions to sucrose compared to control levels after vehicle microinjections (vehicle $=100 \%$; main effect of drug: $\mathrm{F}(2,16)=13.35, p<0.001$ in time-course group; $\mathrm{F}(3,41)=$ $4.11, p<0.05$ in sucrose/quinine group). All three doses of anandamide increased hedonic reactions, and at all three time points tested in the $45 \mathrm{~min}$ after microinjection (details below; Figure 3). Sucrose taste elicited only positive hedonic reactions and hardly any aversive reactions, even after vehicle microinjections. Anandamide selectively amplified the number of positive hedonic reactions elicited by sucrose, and never induced aversive reactions to sucrose.

\section{Hedonic Hotspot Maps for 'Liking' Enhancement}

Plume-sized hexagons matching the sizes of intense, moderate, and low Fos plumes were color-coded to reflect the quality and magnitude of behavioral effects produced by anandamide microinjection at that site, and plotted onto
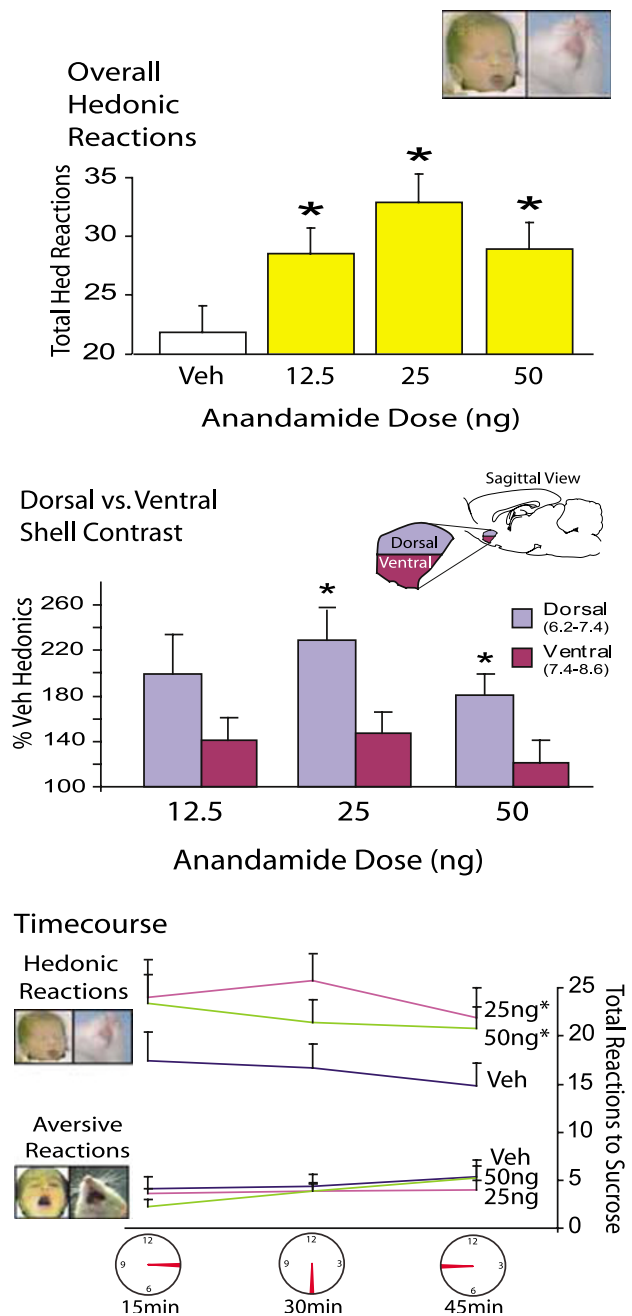

Figure 3 Anandamide enhances positive hedonic reactions to sucrose, particularly in dorsal accumbens shell. Dose-response effect for hedonic enhancement: All doses (12, 25, $50 \mathrm{ng}$ ) of anandamide amplified hedonic 'liking' reactions elicited by a sucrose taste compared to vehicle microinjection at same sites (30 min time point; *p<0.05). Dorsal vs ventral shell contrast: Anandamide (25 and $50 \mathrm{ng}$ ) increased hedonic reactions more at cannulae sites in the dorsal half of the accumbens shell than at sites in the ventral half $(* p<0.05)$. Time course: Anandamide enhancement was similar at all time points tested $(15,30$, and 45 min after microinjection) $* p<0.05$.

each corresponding site location (mapping figures represent anandamide plumes relative to lower, normal tissue baselines, to avoid underestimation of drug spread (Peciña and Berridge, 2005; Smith and Berridge, 2005). Anandamide increased hedonic reactions to sucrose at most microinjection sites, within approximately $2.75 \mathrm{~mm}^{3}$ volume that extended over most of the medial shell. The effective hedonic enhancement zone extended from an anterior level just rostral to the far anterior genu of the corpus callosum in medial shell (Bregma $+2.52 \mathrm{~mm}$ ) to a posterior level at the caudal end of the lateral accumbens shell (Bregma + 1.08; Figures 2 and 4).

\section{Hedonic Hotspot Focus in Dorsal Shell}

A particularly effective hedonic hotspot for enhancing 'liking' reactions to sucrose was found to be concentrated within 
the dorsal portion of medial shell (Figure 3). Sites centered in the dorsal half of the medial shell (dorsal to $7.4 \mathrm{~mm} \mathrm{DV}$ ) produced stronger anandamide enhancements of positive hedonic reactions to sucrose taste than sites in the ventral half of medial shell $(\mathrm{F}(3,17)=4.01, p<0.05$; Figure 3$)$.
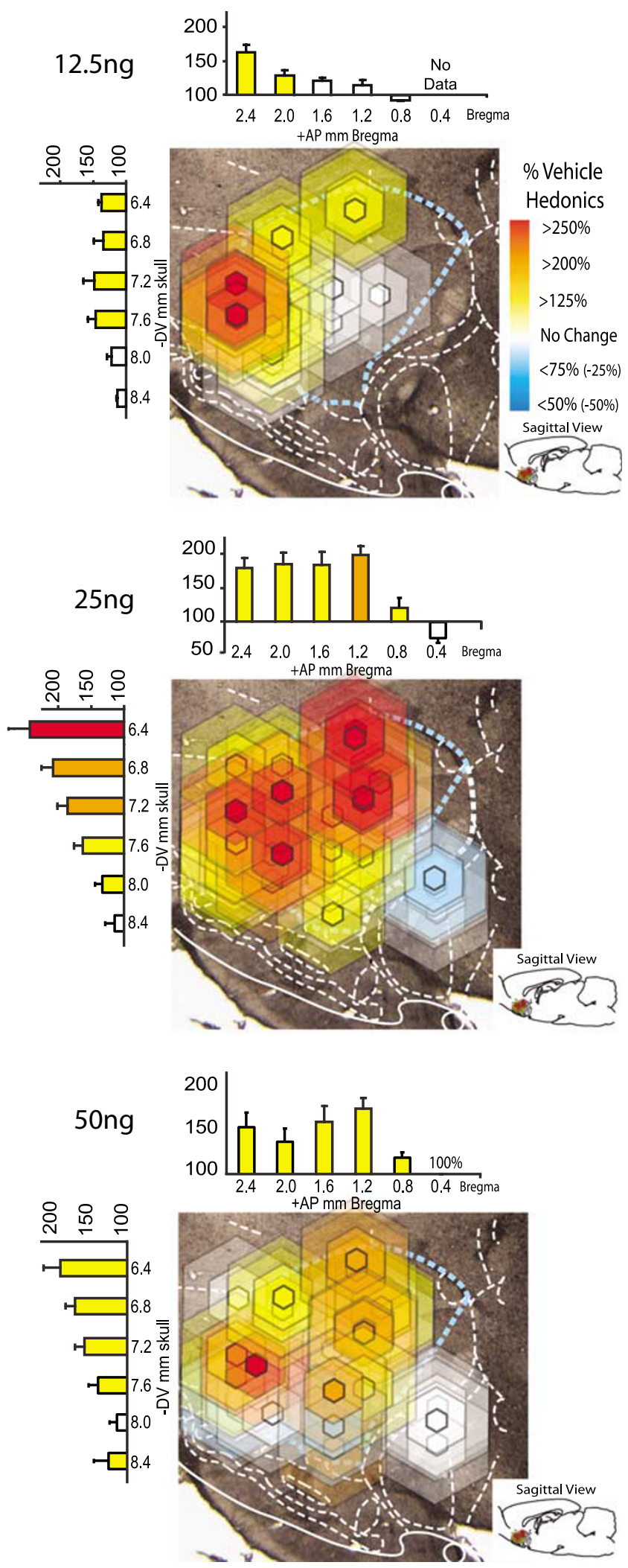

The dorsal hot spot focus was approximately $1.6 \mathrm{~mm}^{3}$ in volume (defined as the zone where anandamide reliably produced increases in positive hedonic reactions $>150 \%$ compared to after vehicle microinjection at the same site). For example, in dorsal shell, injections of $25 \mathrm{ng}$ anandamide more than doubled hedonic reactions relative to vehicle levels $(210 \%)$, while the same dose in ventral shell yielded increases of only $127 \%(t=2.5, p<0.05)$. Similarly, $50 \mathrm{ng}$ anandamide had greater hedonic effects in the dorsal half of shell $(160 \%)$ than in ventral shell $(101 \% ; t=2.2, p<0.05)$, and at a few ventral sites actually seemed to suppress hedonic reactions below vehicle levels (Figure 4). The same dorsoventral pattern appeared as a trend for $12.5 \mathrm{ng}$ anandamide ( $t=1.5$, NS; dorsal: $180 \%$, ventral: $120 \%)$.

Hedonic enhancement was not produced by anandamide at any anatomical control sites in brain structures outside the nucleus accumbens tested here, including dorsal and anterior sites along cannula tracks. Although the outer penumbra of a number of Fos plumes penetrated into accumbens core, limbic cortex, or septum (lowest $2 \times$ and $3 \times$ Fos elevation), $91 \%$ of hedonic Fos plume centers (intense $>10 \times$ Fos elevation) were entirely contained within the medial shell, and $79 \%$ of middle plume zones (moderate $>5 \times$ Fos elevation) were likewise completely contained within the medial shell. While future studies will be needed to identify the Fos threshold for hedonic enhancement, the present results at least indicate that medial shell contained well over $90 \%$ of the total local Fos expression caused by microinjections that enhanced hedonic impact. Finally, no hedonic enhancement was detectable at control sites in dorsal striatum or in anterior prelimbic cortex, nor in anterior ventral pallidum. In fact, when all anatomical control sites were pooled for statistical analysis, anandamide in those structures actually decreased hedonic sucrose reactions to below vehicle levels $(t=3.13, p<0.05)$.

This overall pattern of Fos plumes and anatomical control sites indicates that anandamide acted primarily in the medial accumbens shell to cause amplification of positive hedonic 'liking' reactions elicited by the taste of sucrose.

\section{Dose-Response Effects for Hedonic Impact Enhancement}

All doses of anandamide tested here produced hedonic increases over vehicle control levels (one-way ANOVA on all rats at 30 min time point, $\mathrm{F}(3,73)=5.7, p=0.001)$. Effects of the three doses were of similar magnitudes, although the middle, $25 \mathrm{ng}$ dose was more effective at increasing positive

Figure 4 Anandamide hedonic enhancement: dose maps. Anandamideinduced increases in hedonic reactions to sucrose are shown for each dose separately (12.5, 25, $50 \mathrm{ng}$; all at $30 \mathrm{~min}$ after microinjection). Hedonic enhancement is expressed as within-subject percentage change from vehicle levels for each rat, represented by symbol color. Map symbol size represents uninjected-relative intense $(10 \times)$, moderate $(5 \times)$, and low $(3 x)$ zones of Fos elevation, similar to Figure 2. Dorsal shell advantage: Bars along rostrocaudal and dorsoventral axes show intensity of anandamide effects within each $0.4 \mathrm{~mm}$-wide level (mean \pm SEM percent of vehicle levels); a plume symbol can contribute to more than one bar when it straddles multiple levels). Bar colors reflect mean percentage change from vehicle. Backgrounds stained for Substance P. 
hedonic reactions ( $146 \%$ of vehicle levels) than the highest, $50 \mathrm{ng}$ dose (134\%; $t=2.45, p<0.05$; Figures 2 and 3 ). Further, nearly half of rats (46\%, mostly with ventral cannulae placements) showed no change in positive hedonic reactions after the $50 \mathrm{ng}$ dose $(25 \%$ for $12.5 \mathrm{ng}, 33 \%$ for $25 \mathrm{ng}$ ). This pattern of results suggests that anandamide dose-response effects on hedonic enhancement might have an 'inverted U' shape, similar to cannabinoid drug effects reported for food intake. Further work would be necessary to confirm potential dose-response effects on hedonic impact.

\section{Time Course of Hedonic Enhancements}

Hedonic enhancement was detected at the first taste reactivity test conducted $15 \mathrm{~min}$ after anandamide microinjections $(\mathrm{F}(2,20)=3.52, p<0.05)$, and there was no difference in the magnitude of hedonic enhancement across the time points tested at 15,30 , and $45 \mathrm{~min}$ after microinjection (no main effect of time after infusion $(\mathrm{F}(2,16)=0.788$, NS, or interaction between dose and time of test $(\mathrm{F}(4,32)=0.316$, NS); Figure 3, and Supplementary Figure S1 online). Thus, anandamide-induced hedonic enhancements appear to occur early within $15 \mathrm{~min}$ after microinjection and remain robust and stable at least across the entire ensuing $45 \mathrm{~min}$.

\section{Analysis of Hedonic Components of Taste Reactivity}

When positive hedonic reactions were broken into orofacial components, anandamide significantly increased midline tongue protrusions $(\mathrm{F}(2,28)=14.9, p<0.001$; individual doses: $25 \mathrm{ng}: t=4.0, p<0.01$; $50 \mathrm{ng}: t=2.7, p<0.05)$ and lateral tongue protrusions elicited by sucrose $(\mathrm{F}(2,28)=5.1$, $p<0.05 ; 25 \mathrm{ng}: t=1.6, p=0.12$; $50 \mathrm{ng}: t=2.0, p=0.06)$. Paw licks were additionally increased by the $25 \mathrm{ng}$ dose $(\mathrm{F}(2,28)=2.6, p=0.09 ; 25 \mathrm{ng}: t=3.0, p<0.01 ; 50 \mathrm{ng}: t=1.1$, NS; Supplementary Figure S2 online).

\section{Anandamide does not Affect Aversive Reactivity to Quinine}

In contrast to the robust hedonic enhancement of positive reactions elicited by sucrose taste, anandamide had no significant effect on aversive reactions to quinine taste $(\mathrm{F}(3,27)=1.7, \mathrm{NS}$; at any dose: $12.5 \mathrm{ng}: t=1.2, \mathrm{NS} ; 25 \mathrm{ng}$ : $t=1.8$, NS; 50 ng: $t=0.2$, NS; Supplementary Figures S3, S4 online). Oral infusions of bitter quinine elicited primarily aversive reactions, and never more than a few positive reactions. Anandamide did not change the low level of positive reactions to quinine $(\mathrm{F}(3,27)=0.4$, NS). After $15-$ $30 \mathrm{~s}$ of quinine infusion, rats typically switched from active aversive reactions (eg, gapes) to passive dripping of the quinine solution from their mouths (often accompanied by forelimb flailing and head shaking, possibly elicited as a grooming response by solution dripping on animals' paws and fur). Since the transition to passive dripping may have obscured more active aversive responses, we also examined the initial $10 \mathrm{~s}$ of responding, before passive dripping began. Again, anandamide did not alter negative aversive reactions at any dose (aversive reactions: $\mathrm{F}(3,18)=1.6$, NS; Supplementary Figure S4 online). Thus, anandamide microinjec-

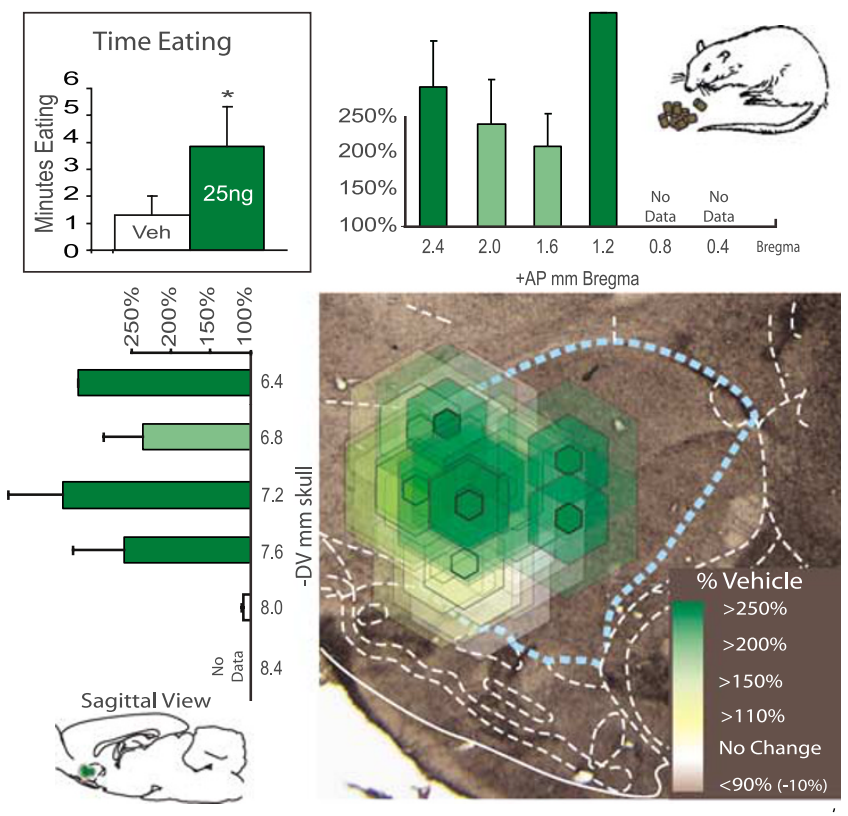

Figure 5 Anandamide stimulates voluntary eating. Time eating: Anandamide microinjections increased the cumulative duration of eating bouts (measured during I h). Time eating map: Eating duration increases for each rat were mapped onto symbols as in Figure 4 ( $25 \mathrm{ng}$ dose of anandamide compared to vehicle at same sites). Anandamide stimulated food intake at most sites throughout the medial shell.

tions in medial shell of nucleus accumbens failed to alter the negative aversive impact of the taste of quinine, even when the same microinjections enhanced the positive hedonic impact of the taste of sucrose for the same rats.

\section{Anandamide Increases Eating Behavior and Food Intake}

Anandamide (25 ng) increased spontaneous voluntary eating behavior and food intake (Figures 2 and 5). Anandamide microinjections in the medial shell more than doubled the cumulative duration of time spent eating $(254 \%$ of vehicle levels, $t=2.36, p<0.05$; Figure 5). Intake was stimulated by anandamide at sites in dorsal shell that also enhanced 'liking', and possibly extended into a few ventral shell sites as well. However, we caution that it would be premature to draw conclusions about site differences for 'wanting' $v s$ 'liking', since the effects were tested in different rats, and there were not many discrepancies between groups. Overall for the entire group, anandamide similarly doubled the number of eating bouts $(203 \%$ of vehicle, $t=2.52, p<0.05$; Supplementary Figure S5 online), and produced a $600 \%$ increase in chow intake in rats that ate at all on either day $(t=2.6, p<0.05)$. Anandamide did not produce detectable changes in the amount of uneaten crumbs or latency to begin eating, changes in water intake or time spent drinking, or in non-ingestive behaviors such as object gnawing, object sniffing, food carrying, and sleeping (eating latency: $t=1.1$, NS; time drinking: $t=0.13$, NS; drinking bouts: $t=0.10$, NS; sniffing: $t=1.4$, NS; food carrying: $t=0.4, \mathrm{NS}$; sleeping: $t=0.15$, NS). Overall, these results regarding spontaneous behaviors confirm that delivery of anandamide to a hedonic hotspot in medial shell of nucleus accumbens stimulates food eating 
in most rats, but does not increase water drinking or various other behaviors.

\section{DISCUSSION}

\section{Intra-Accumbens Shell Anandamide Specifically Enhances Taste 'Liking'}

These results demonstrate that anandamide stimulation of a roughly $2.75 \mathrm{~mm}^{3}$ volume of medial shell of nucleus accumbens (and especially a $1.6 \mathrm{~mm}^{3}$ hotspot in its dorsal half) acts to amplify the hedonic impact of a natural sensory reward, sweetness. Anandamide microinjections in the dorsal hotspot more than doubled the number of hedonic 'liking' reactions elicited by the taste of a sucrose solution that was infused into the mouth (compared with reaction levels after vehicle microinjections). Hedonic enhancement appeared rapidly within $15 \mathrm{~min}$ after anandamide microinjection, persisted at all tests throughout the ensuing $45 \mathrm{~min}$, and was robust after all anandamide doses tested here.

Anandamide did not alter aversive 'disliking' reactions to a bitter quinine taste, even when the same microinjections enhanced 'liking' reactions to sucrose on the same day. This selective enhancement pattern indicates that endocannabinoids specifically amplify the positive hedonic impact of reward without changing the negative aversive impact of unpleasant stimuli. In other words, endocannabinoid stimulation appeared to selectively make sweetness become even more positively 'liked,' but did not reliably improve or worsen an unpalatable bitter taste. This suggests a 'rich get richer' form of reward amplification by endocannabinoid action in the nucleus accumbens, in which the most pleasant stimuli gain even greater hedonic value while other stimuli that are less 'liked' to begin with remain relatively unchanged. If so, that might help explain why cannabinoidstimulated increases in intake in rats and humans appear to be targeted specifically toward already palatable foods (eg sweet or high fat) more than to other less-palatable foods (Foltin et al, 1988; Koch and Matthews, 2001).

\section{Anandamide Hedonic Hotspot is within Nucleus Accumbens}

It seems reasonable to conclude from our results that the medial shell of nucleus accumbens, especially its dorsal region, contained the hedonic hotspot responsible for the observed endocannabinoid enhancement of 'liking' for sweetness. Intense Fos plumes for our hedonic sites were essentially contained within the nucleus accumbens shell, and the vast majority did not protrude significantly into other brain structures. In addition, anatomical control sites in dorsal striatum, ventral pallidum, and prelimbic cortex did not produce any detectable anandamide enhancement of hedonic impact outside the nucleus accumbens, further supporting anatomical localization of hedonic endocannabinoid mechanisms in the accumbens shell. This does not mean that no other cannabinoid hedonic hotspots will eventually be found in other brain structures, but does mean that the endocannabinoid hedonic effects reported here are likely to be mediated by a hotspot within the medial shell of nucleus accumbens.
The present data further indicate that anandamide microinjections in accumbens that enhance taste 'liking' may also promote appetitive 'wanting' of food, as measured by food consumption behavior, consistent with previous reports of cannabinoid-modulation of appetitive motivation (Williams and Kirkham, 2002a, b; Thornton-Jones et al, 2005).

\section{Hottest Spot in Dorsal Medial Shell}

We found evidence that the most intense hedonic enhancement by anandamide was produced in a localized hotspot contained specifically within the dorsal half of the medial shell. Here we operationally defined a hedonic hotspot as an anatomical concentration of sites where anandamide produced $>150 \%$ increases in 'liking' reactions to sucrose. Microinjection sites in a $1.6 \mathrm{~mm}^{3}$ hotspot of the dorsal shell were significantly more potent than sites in the ventral shell for amplifying positive 'liking' reactions to sucrose. For example, within that dorsal spot, the most effective anandamide dose $(25 \mathrm{ng})$ reliably caused a greater than doubling of the number of 'liking' reactions elicited by sucrose, whereas such enhancements rarely occurred at more ventral sites. In addition, high-dose anandamide at some ventral sites in medial shell actually appeared to suppress sucrose 'liking' reactions below control levels, whereas hedonic suppression was never observed at dorsal accumbens sites. The $1.6 \mathrm{~mm}^{3}$ dorsal hottest spot composed approximately $50 \%$ of total medial shell volume (medial shell = approximately $3 \mathrm{~mm}^{3}$ ). Overall, this suggests that the dorsal medial shell contains an especially potent hotspot for endocannabinoid magnification of the hedonic impact of sweetness (and tentatively that ventral shell could contain an opposite 'coldspot' where the same endocannabinoid stimulation can sometimes even dampen reactions to a sensory pleasure).

The $1.6 \mathrm{~mm}^{3}$ hedonic hotspot for anandamide enhancement of hedonic impact intriguingly overlaps with a roughly $1 \mathrm{~mm}^{3}$ opioid hedonic hotspot that was previously mapped in the dorsal rostral quadrant of medial shell by another taste reactivity study in our laboratory (where the $\mu$ opioid agonist DAMGO amplified 'liking' reactions (Peciña and Berridge, 2005)). The anandamide hedonic hotspot identified here completely covered that opioid hedonic hotspot in the dorsal rostral quadrant, and possibly extended beyond it caudally throughout most of the dorsal half of medial shell. We did not observe rostrocaudal differences for anandamide effects in medial shell here, unlike for previously reported reward-related effects of opioid, GABA, glutamate, and $\Delta^{9}$-THC microinjections in medial shell (Reynolds and Berridge, 2002, 2003; Peciña and Berridge, 2005; Zangen et al, 2006).

However, we caution that it may be premature to draw strong conclusions about precise relative boundaries of endocannabinoid $v s$ opioid hotspots, or about the existence or lack of endocannabinoid rostrocaudal effects, because we mapped larger Fos plumes here than in the previous opioid mapping study. One reason is that to maximize the chance of successful endocannabinoid hedonic amplification, we deliberately chose large microinjection volumes $(0.5 \mu \mathrm{l})$ that were over twice the volume used for DAMGO microinjections in the previous study $(0.2 \mu \mathrm{l})$ (Peciña and Berridge, 2005). The larger volumes used here might therefore have led to relative 
overestimation of endocannabinoid hotspot borders, and obscured some finer details of its inner structure. These issues could be resolved by future direct comparisons of endocannabinoid and opioid hedonic hotspots using smaller drug microinjection volumes, and the same rats.

It also may be premature to draw conclusions about the specific receptor mechanisms of hedonic hotspot effects of anandamide. Reward-related effects of anandamide are often viewed to be mediated by CB1 receptors (Piomelli, 2003; Cheer et al, 2004; De Vries and Schoffelmeer, 2005; Gardner, 2005; Kirkham, 2005; Thornton-Jones et al, 2005; Zangen et al, 2006). However, other CB receptor and even nonreceptor neuronal targets have been proposed for anandamide, some of which are present in the accumbens shell (for reviews, see Di Marzo et al, 2002; Pertwee, 2005). Additional experiments, perhaps involving the use of selective $\mathrm{CB} 1$ and $\mathrm{CB} 2$ agonists or antagonists, will be required in order to confirm the role of $\mathrm{CB} 1$ receptors in the effects of anandamide reported here.

At present, it seems safe to conclude simply that endocannabinoid and opioid hedonic hotspots anatomically overlap in the dorsal medial shell, and that CB1 receptors in the accumbens hotspot are the leading candidate to mediate hedonic enhancement by anadamide. Anatomical overlap suggests the possibility that both endocannabinoid and opioid signals might act on the same local circuits to amplify hedonic impact. It is of interest that $\mathrm{CB} 1$ receptors and opioid receptors are reported to interact, can occur in the same striatal synapses, and even be colocalized on the same neurons in nucleus accumbens shell and core (Tanda et al, 1997; Hohmann and Herkenham, 2000; Rodriguez et al, 2001; Pickel et al, 2004; Caille and Parsons, 2006). If colocalization occurs in hotspot neurons, this would support the possibility that endocannabinoid and opioid neurochemical signals in nucleus accumbens might interact to enhance 'liking' reactions to the sensory pleasure of sucrose.

\section{CONCLUSIONS}

These results provide the first demonstration that endocannabinoids in the nucleus accumbens specifically amplify the hedonic impact of a prototypical sensory pleasure, sweetness. Anandamide acted especially in a dorsal hotspot of medial shell in nucleus accumbens to enhance positive 'liking' reactions to a rewarding sucrose taste. It would be of interest to know whether other types of sensory pleasure besides sweetness can be enhanced by the endocannabinoid hedonic hotspot described here, and whether the rewarding and euphoric effects of exogenous cannabinoid drugs such as $\Delta^{9}$ THC are mediated by the same endocannabinoid hedonic hotspot that amplifies taste 'liking'. Food intake was also stimulated by anandamide microinjections that amplified hedonic 'liking', suggesting that magnifying the pleasurable impact of food reward might be part of the mechanism for cannabinoid promotion of appetite or incentive motivation. Endocannabinoid hedonic hotspots for sensory pleasures may thus be important to understanding how the brain normally processes pleasurable natural rewards and generates incentive motivation. Dysfunction of endocannabinoid hedonic/motivational mechanisms highlighted here might also be relevant to understanding what goes awry in certain hedonic or appetitive disorders such as depression, drug addiction, and obesity.

\section{ACKNOWLEDGEMENTS}

This work was supported by National Institutes of Health Grants DA015188 and MH063649. SVM and KSS were supported by NIH training grant DC00011, and SVM by NIDA NRSA DA021481. We thank Phillip Hoberg for assistance with Fos staining, and the anonymous reviewers for their helpful comments and suggestions.

\section{REFERENCES}

Bakshi VP, Kelley AE (1993). Striatal regulation of morphineinduced hyperphagia: an anatomical mapping study. Psychopharmacology (Berl) 111: 207-214.

Berridge CW, Stratford TL, Foote SL, Kelley AE (1997). Distribution of dopamine beta-hydroxylase-like immunoreactive fibers within the shell subregion of the nucleus accumbens. Synapse 27: 230-241.

Berridge KC (2000). Measuring hedonic impact in animals and infants: microstructure of affective taste reactivity patterns. Neurosci Biobehav Rev 24: 173-198.

Berridge KC, Flynn FW, Schulkin J, Grill HJ (1984). Sodium depletion enhances salt palatability in rats. Behav Neurosci 98: 652-660.

Berridge KC, Robinson TE (2003). Parsing reward. Trends Neurosci 26: 507-513.

Caille S, Parsons LH (2006). Cannabinoid modulation of opiate reinforcement through the ventral striatopallidal pathway. Neuropsychopharmacology 31: 804-813.

Cheer JF, Wassum KM, Heien ML, Phillips PE, Wightman RM (2004). Cannabinoids enhance subsecond dopamine release in the nucleus accumbens of awake rats. J Neurosci 24: 4393-4400.

Cooper SJ (2004). Endocannabinoids and food consumption: comparisons with benzodiazepine and opioid palatabilitydependent appetite. Eur J Pharmacol 500: 37-49.

Cota D, Tschop MH, Horvath TL, Levine AS (2006). Cannabinoids, opioids and eating behavior: the molecular face of hedonism? Brain Res Brain Res Rev 51: 85-107.

De Vries TJ, Schoffelmeer AN (2005). Cannabinoid CB1 receptors control conditioned drug seeking. Trends Pharmacol Sci 26: 420-426.

Di Marzo V, De Petrocellis L, Fezza F, Ligresti A, Bisogno T (2002). Anandamide receptors. Prostaglandins Leukot Essent Fatty Acids 66: 377-391.

Di Marzo V, Goparaju SK, Wang L, Liu J, Batkai S, Jarai Z et al (2001). Leptin-regulated endocannabinoids are involved in maintaining food intake. Nature 410: 822-825.

Di Marzo V, Matias I (2005). Endocannabinoid control of food intake and energy balance. Nat Neurosci 8: 585-589.

Di Marzo V, Petrocellis LD (2006). Plant, synthetic, and endogenous cannabinoids in medicine. Annu Rev Med 57: 553-574.

Foltin RW, Fischman MW, Byrne MF (1988). Effects of smoked marijuana on food intake and body weight of humans living in a residential laboratory. Appetite 11: 1-14.

Fusco FR, Martorana A, Giampa C, De March Z, Farini D, D’Angelo $\mathrm{V}$ et al (2004). Immunolocalization of CB1 receptor in rat striatal neurons: a confocal microscopy study. Synapse 53: 159-167.

Gardner EL (2005). Endocannabinoid signaling system and brain reward: emphasis on dopamine. Pharmacol Biochem Behav 81: 263-284.

Gong JP, Onaivi ES, Ishiguro H, Liu QR, Tagliaferro PA, Brusco A et al (2006). Cannabinoid CB2 receptors: immunohistochemical localization in rat brain. Brain Res 1071: 10-23. 
Grill HJ, Norgren R (1978). The taste reactivity test. I. Mimetic responses to gustatory stimuli in neurologically normal rats. Brain Res 143: 263-279.

Harrold JA, Elliott JC, King PJ, Widdowson PS, Williams G (2002). Down-regulation of cannabinoid-1 (CB-1) receptors in specific extrahypothalamic regions of rats with dietary obesity: a role for endogenous cannabinoids in driving appetite for palatable food? Brain Res 952: 232-238.

Herkenham M, Lynn AB, de Costa BR, Richfield EK (1991). Neuronal localization of cannabinoid receptors in the basal ganglia of the rat. Brain Res 547: 267-274.

Higgs S, Williams CM, Kirkham TC (2003). Cannabinoid influences on palatability: microstructural analysis of sucrose drinking after delta(9)-tetrahydrocannabinol, anandamide, 2-arachidonoyl glycerol and SR141716. Psychopharmacology (Berl) 165: 370-377.

Hohmann AG, Herkenham M (2000). Localization of cannabinoid $\mathrm{CB}(1)$ receptor mRNA in neuronal subpopulations of rat striatum: a double-label in situ hybridization study. Synapse 37: 71-80.

Hsu SM, Raine L, Fanger H (1981). Use of avidin-biotinperoxidase complex $(\mathrm{ABC})$ in immunoperoxidase techniques: a comparison between $\mathrm{ABC}$ and unlabeled antibody (PAP) procedures. J Histochem Cytochem 29: 577-580.

Ikemoto S, Wise RA (2004). Mapping of chemical trigger zones for reward. Neuropharmacology 47(Suppl 1): 190-201.

Jarrett MM, Limebeer CL, Parker LA (2005). Effect of delta9tetrahydrocannabinol on sucrose palatability as measured by the taste reactivity test. Physiol Behav 86: 475-479.

Kirkham TC (2005). Endocannabinoids in the regulation of appetite and body weight. Behav Pharmacol 16: 297-313.

Kirkham TC, Williams CM (2001). Synergistic effects of opioid and cannabinoid antagonists on food intake. Psychopharmacology (Berl) 153: 267-270.

Kirkham TC, Williams CM, Fezza F, Di Marzo V (2002). Endocannabinoid levels in rat limbic forebrain and hypothalamus in relation to fasting, feeding and satiation: stimulation of eating by 2-arachidonoyl glycerol. Br J Pharmacol 136: 550-557.

Koch JE, Matthews SM (2001). Delta9-tetrahydrocannabinol stimulates palatable food intake in Lewis rats: effects of peripheral and central administration. Nutr Neurosci 4: 179-187.

Matyas F, Yanovsky Y, Mackie K, Kelsch W, Misgeld U, Freund TF (2006). Subcellular localization of type 1 cannabinoid receptors in the rat basal ganglia. Neuroscience 137: 337-361.

Moldrich G, Wenger T (2000). Localization of the CB1 cannabinoid receptor in the rat brain. An immunohistochemical study. Peptides 21: 1735-1742.

Muller R, Bravo R, Burckhardt J, Curran T (1984). Induction of $\mathrm{c}$-fos gene and protein by growth factors precedes activation of c-myc. Nature 312: 716-720.

Navarro M, Carrera MR, Fratta W, Valverde O, Cossu G, Fattore L et al (2001). Functional interaction between opioid and cannabinoid receptors in drug self-administration. J Neurosci 21: 5344-5350.

Pagotto U, Marsicano G, Cota D, Lutz B, Pasquali R (2006). The emerging role of the endocannabinoid system in endocrine regulation and energy balance. Endocr Rev 27: 73-100.

Paxinos G, Watson C (1998). The Rat Brain in Stereotaxic Coordinates. Academic Press: San Diego.

Paxinos G, Watson C (2005). The Rat Brain in Stereotaxic Coordinates. Elsevier: Amsterdam.

Peciña S, Berridge KC (2000). Opioid site in nucleus accumbens shell mediates eating and hedonic 'liking' for food: map based on microinjection Fos plumes. Brain Res 863: 71-86.

Peciña S, Berridge KC (2005). Hedonic hot spot in nucleus accumbens shell: where do mu-opioids cause increased hedonic impact of sweetness? J Neurosci 25: 11777-11786.
Pertwee RG (2005). Pharmacological actions of cannabinoids. Handbook Exp Pharmacol 168: 1-51.

Pickel VM, Chan J, Kash TL, Rodriguez JJ, MacKie K (2004). Compartment-specific localization of cannabinoid 1 (CB1) and mu-opioid receptors in rat nucleus accumbens. Neuroscience 127: $101-112$.

Piomelli D (2003). The molecular logic of endocannabinoid signalling. Nat Rev Neurosci 4: 873-884.

Reynolds SM, Berridge KC (2002). Positive and negative motivation in nucleus accumbens shell: bivalent rostrocaudal gradients for GABA-elicited eating, taste 'liking'/'disliking' reactions, place preference/avoidance, and fear. J Neurosci 22: 7308-7320.

Reynolds SM, Berridge KC (2003). Glutamate motivational ensembles in nucleus accumbens: rostrocaudal shell gradients of fear and feeding. Eur J Neurosci 17: 2187-2200.

Rodriguez JJ, Mackie K, Pickel VM (2001). Ultrastructural localization of the CB1 cannabinoid receptor in mu-opioid receptor patches of the rat caudate putamen nucleus. $J$ Neurosci 21: 823-833.

Rowland NE, Mukherjee M, Robertson K (2001). Effects of the cannabinoid receptor antagonist SR 141716, alone and in combination with dexfenfluramine or naloxone, on food intake in rats. Psychopharmacology (Berl) 159: 111-116.

Schoffelmeer AN, Hogenboom F, Wardeh G, De Vries TJ (2006). Interactions between $\mathrm{CB} 1$ cannabinoid and mu opioid receptors mediating inhibition of neurotransmitter release in rat nucleus accumbens core. Neuropharmacology 51: 773-781.

Smith KS, Berridge KC (2005). The ventral pallidum and hedonic reward: neurochemical maps of sucrose 'liking' and food intake. J Neurosci 25: 8637-8649.

Solinas M, Goldberg SR (2005). Motivational effects of cannabinoids and opioids on food reinforcement depend on simultaneous activation of cannabinoid and opioid systems. Neuropsychopharmacology 30: 2035-2045.

Tanda G, Pontieri FE, Di Chiara G (1997). Cannabinoid and heroin activation of mesolimbic dopamine transmission by a common mul opioid receptor mechanism. Science 276: 2048-2050.

Thornton-Jones ZD, Vickers SP, Clifton PG (2005). The cannabinoid CB1 receptor antagonist SR141716A reduces appetitive and consummatory responses for food. Psychopharmacology (Berl) 179: $452-460$.

Verty AN, Singh ME, McGregor IS, Mallet PE (2003). The cannabinoid receptor antagonist SR 141716 attenuates overfeeding induced by systemic or intracranial morphine. Psychopharmacology (Berl) 168: 314-323.

Vigano D, Rubino T, Parolaro D (2005). Molecular and cellular basis of cannabinoid and opioid interactions. Pharmacol Biochem Behav 81: 360-368.

Williams CM, Kirkham TC (1999). Anandamide induces overeating: mediation by central cannabinoid (CB1) receptors. Psychopharmacology (Berl) 143: 315-317.

Williams CM, Kirkham TC (2002a). Observational analysis of feeding induced by delta9-THC and anandamide. Physiol Behav 76: $241-250$

Williams CM, Kirkham TC (2002b). Reversal of delta9-THC hyperphagia by SR141716 and naloxone but not dexfenfluramine. Pharmacol Biochem Behav 71: 333-340.

Williams CM, Rogers PJ, Kirkham TC (1998). Hyperphagia in pre-fed rats following oral delta9-THC. Physiol Behav 65 343-346.

Zangen A, Solinas M, Ikemoto S, Goldberg SR, Wise RA (2006). Two brain sites for cannabinoid reward. J Neurosci 26: 4901-4907.

Zhang M, Kelley AE (2000). Enhanced intake of high-fat food following striatal mu-opioid stimulation: microinjection mapping and fos expression. Neuroscience 99: 267-277.

Supplementary Information accompanies the paper on the Neuropsychopharmacology website (http://www.nature.com/npp) 